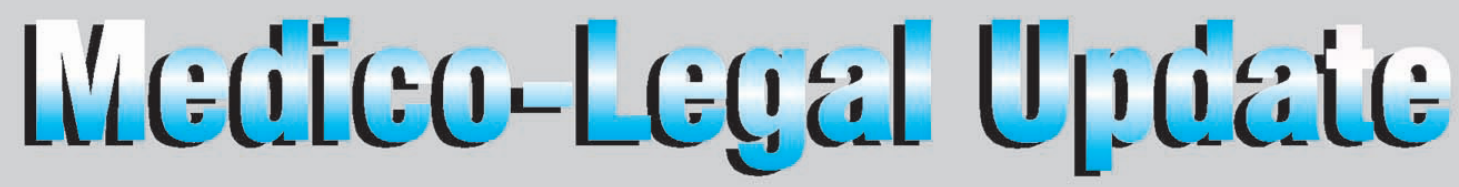

\section{An International Journal}

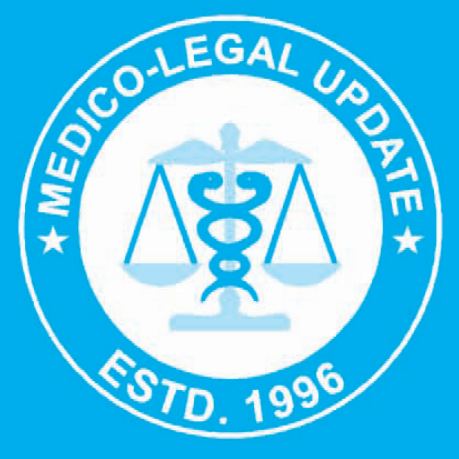




\title{
Medico-Legal Update
}

\author{
Editor-in Chief
}

Prof. (Dr) R K Sharma

Former Head, Department of Forensic Medicine \& Toxicology

All-India Institute of Medical Sciences, New Delhi-110029

E-mail: medicolegalupdate@gmail.com

\section{ASSOCIATE EDITOR}

1. S.K. Dhattarwal (Professor) Forensic Medicine, PGIMS, Rohtak, Haryana

2. Dr. Adarsh Kumar (Additional Professor) Forensic Medicine, AlIMS, New Delhi

3. Dr. Vijaynath V (Associate Professor) Forensic Medicine, Vinayaka Mission Medical college, Tamil Nadu

4. Ms. Roma Khan, Forensic Sciences, INSAAF Mumbai

5. Dr. Imran Sabri (Assistant Professor) Department of Bio-Medical Sciences.College of Medicine, King Faisal University,Saudi Arabia

\section{INTERNATIONAL EDITORIAL ADVISORY BOARD}

1. B. N. Yadav (Professor) Forensic Medicine, BP Koirala Institute of Medical Sciences, Nepal

2. Dr. Vasudeva Murthy Challakere Ramaswam (Senor Lecturer) Department of Pathology, International Medical University, Bukit Jalil, Kuala Lumpur. Malaysia

3. Babak Mostafazadeh (Associate Professor) Department of Forensic Medicine \& Toxicology, Shahid Beheshti University of Medical Sciences, Tehran-Iran

4. Dr. Sarathchandra Kodikara (Lecturer) Forensic Medicine Department of Forensic Medicine, Faculty of Medicine, University of Peradeniya, Sri Lanka

\section{NATIONAL EDITORIAL ADVISORY BOARD}

1. Prof. N.K. Agarwal (Professor) Forensic Medicine, UCMS, Delhi

2. P.K. Chattopadhyay, (Professor) Forensic Sciences, Amity University, Noida

3. Dalbir Singh (Professor) Forensic Medicine, PGIMER, Chandigarh

4. Dr. Harish Pathak, Mumbai

5. J. Gargi (Professor) GGS Medical College, Faridkot

6. P.C. Dikshit (Professor) Forensic Medicine, Jamia Hamdard Medical College, New Delhi

7. Anil Mittal (Professor) Forensic Medicine, Vardhman Mahavir Medical college, New Delhi

8. Balbir Kaur (Professor) Forensic Medicine, MM institute of Medical Sciences, Ambala

9. Mukesh Yadav (Professor) Forensic Medicine, School of Medical Sciences and research,Greater Noida

10. T.K.K. Naidu (Professor) Forensic Medicine, Prathima Institute of Medical Sciences Andhra Pradesh

11. S. Das (Professor) Forensic Medicine, Himalayan Institute of Medical Sciences Dehradun

12. Col Ravi Rautji, Forensic Medicine, Armed Forces Medical College, Pune

13. Dr. Manish Nigam (Professor and Head) Department of Forensic Medicine \& Toxicology Sri Aurobindo Institute of Medical Sciences, INDORE (M.P.)

14. Dr. Shailesh Kudva (Principal) Rajasthan Dental College and Hospital Jaipur-302026

15. Usmanganishah Makandar (Associate Professor) Anatomy, AIMS, Bhatinda

16. Dr. Pratik Patel (Professor and Head) Forensic Medicine, Smt NHL Municipal Medical College Ahmedabad

17. Basappa S. Hugar (Associate Professor) Forensic Medicine, Ramaiah Medical College, Bangalore

\section{NATIONAL EDITORIAL ADVISORY BOARD}

18. Dr. Vandana Mudda (Awati) (Associate Prof) Dept of FMT, M.R. Medical College, Gulbarga, Karnataka, India

19. Dr. HarishKumar. N. (AssociateProfessor) Dept.of ForensicMedicine, Sri Siddhartha MedicalCollege, Tumkur

20. Dr. Gowri Shankar (Associate Professor) Forensic Medicine, SNMC, Bagalkot

21. Dr. Manjunath Badni (Reader) Dept of Oral pathology Maharana Pratap college of Dentistry and Research Centre, Gwalior

22. Dr. L.Ananda Kumar (Associate Professor) Forensic Medicine, Rajiv Gandhi Institute of Medical Sciences, (RIMS), Kadapa

23. Dr. Ramesh Nanaji Wasnik (Associate Professor and Head) Forensic Medicine Late B.R.K.M. Govt. Medical college, Jagdalpur

24. Dr. Sachin Sinha (Reader), Dept. of Oral Pathology \& Microbiology Daswani Dental College \& Research Centre, Rajasthan

25. Dr.Sasi Kanth, Asst. Professor, A.C.S.R Government Medical College, Nellore, Andhra Pradesh.

Medico Legal Update is a scientific journal which brings latest knowledge regarding changing medico legal scenario to its readers. The journal caters to specialties of Forensic Medicine, Forensic Science, DNA fingerprinting, Toxicology, Environmental hazards, Sexual Medicine etc. The journal has been assigned international standard serial number (ISSN) 0971-720X. The journal is registered with Registrar of Newspaper for India vide registration numbers 63757/96 under Press and Registration of Books act, 1867. The journal is also covered by EMBASE (Excerpta Medica Database) from 1997 and by INDEX COPERNICUS, POLAND. Medico legal update is a half yearly peer reviewed journal. The journal has also been assigned E-ISSN 0973-1283 (Electronic version). The first issue of the journal was published in 1996

\section{Website: www.medicolegalupdate.org}

(c) All Rights reserved The views and opinions expressed are of the authors and not of the Medico Legal Update. The Medico Legal Update does not guarantee directly or indirectly the quality or efficacy of any products or service featured in the advertisement in the journal, which are purely commercial.

Editor

Dr. R.K. Sharma Institute of Medico-legal Publications 501, Manisha Building 75-76, Nehru Place, New Delhi-110 019

Printed, published and owned by

Dr. R.K. Sharma Institute of Medico-legal Publications 501, Manisha Building, 75-76, Nehru Place, New Delhi-110 019

Published at Institute of Medico-legal Publications 501, Manisha Building 75-76, Nehru Place, New Delhi-110 019 


\section{Medico-Legal Update}

Www.medicolegalupdate.org

CONTENTS

\section{Volume 18, Number 2}

July-December 2018

1. Middle Finger Length is a Good Measure to Predict the Human Stature-

An Experience from a Cross-Sectional Study at a Rural Community in India

Arijit Datta, Vina Vaswani, Chndra Prakash Bhaisora, Preeti Tiwari

2. Histopathological Differentiation of Abrasion, Electrocution and Flame Burns

Rishi Kumar Solanki, Arun Kumar Siddamsetty, Suresh Chand, Sunil Kumar Khanna, P C Dikshit

3. External Findings in Deaths Due to Hanging at NSCB Medical College, Jabalpur, MP

Ashok B Najan, Nidhi Sachdeva, Vivek Srivastava

4. Cephalic Index of Southern Kerala Population-An Autopsy Study

Augustus Joseph, Meena K S, Sharija S

5. Estimation of Stature From Skull Dimensions of Southern Kerala Population-An Autopsy Study

Augustus Joseph, Meena K S, Sharija S

6. A Case Report of Sudden Death Due Rupture of Syphilitic Aneurysm of the Ascending Aorta Avinash H. Waghmode, Pratik M. Chide

7. Five-Year Retrospective Analysis of Profile of Firearm Deaths in Pune Region

Tatiya Harish S, Taware Ajay A, Bandgar Abhijit L, Punpale Satyanarayan B, Jadhao Vijay T

8. About a Case of Anomalous Evolution of the Thanatological Phenomena

Bartolo Caggiano, Matteo Solinas, Francesco Raschellà, Alessandro Feola, Silvestro Mauriello,

Saverio Potenza, Luigi T. Marsella

9. Study of Suicide in Central India

Dinesh S Akarte, M. S Vyawahare MD

10. "Study of The Pattern of Deaths Due to Suicidal Poisoning" at Rims Kadapa, AP

G Mahender, Brethis, G. Damodar, L. Ananda Kumar, Padmini Yadavalli

11. Radiological Age Estimation From the Fusion of Medial Epiphysis of Clavicle

Jatinder Pal Singh, Gurmanjit Rai Maan

12. Study of Patterns Injuries in cases of Vehicular Accidents in Jamnagar region of Gujarat

S. B. Bhatt, J. A. Tanna

13. Study of Co-relation between Hand length, Hand Breadth \& Arm span to Height

J. A. Darji, J. A. Tanna

14. Rights and Responsibilities of The Patient in Health Care System

K. Srinivasulu, B. Dedipya, B. Mrudula 
15. Liability for Medical Negligence Under Consumer Protection Act. 1986 63 Kaibalya Panda, Pragyan Paramita Tripathy

16. Profile of Medico-legal Cases Admitted in the Department of Emergency F.H.M.C., Tundla, Uttar Pradesh

Umar Bin Abdul Aziz, Mohd Kaleem Khan, Tarun K Singh, Mukesh K Goyal

17. Profile of Various Thermal Injury Deaths Across the Three Genders in North Maharashtra 71 Kapileshwar M. Chaudhari, Nilesh A. Devraj, Ajit G. Pathak, Ramesh K. Gadhari

18. Determination of Sex From The Human Adult Sternum: An Autopsy Based Study 77 Manjunatha K, Viswanathan $K G$, Chandan V, Narasimhamurthy

19. Cardiac Causes of Sudden Natural Death in Adults Autopsied in A Tertiary Level Hospital within A One Year Period-A Cross Sectional Study

Salini R, Meena K. S.

20. Handling of Medicolegal Cases by Doctors in Imphal West 86 Abdul Raoof M P, Gitashree Dutta, Th. Meera, Brogen Singh Akoijam, A. Mercy

21. Fatal Road Traffic Accidents: A Study of Autopsied Cases

Mohd Amjad Bhat ${ }^{1}$, Sarvjit Singh Sandhu', Pardeep Singh ${ }^{3}{ }^{90}$

22. Comparison of Two DNA Extraction Methods andTheir Utility in

Forensic Examination of Bone Samples

Naresh Kumar, Pooja Puri, Dhruv Sharma, S. K. Shukla

23. Awareness of Rights of Patient among Patients Admitted in Tertiary Care Charitable HospitalA Cross Sectional Study

Somashekhar S. Pujar, Pushpa.M. G., Vishal Koulapur, Ravindra Honnungar, Prasanna S Jirli

24. Socio-Demographic Profile of Violent Asphyxial Death Cases in Ajmer, Rajasthan

R K Boyal, Shiv Kochar

25. Study of Nature of Ligature Material, Knot Type and Pattern of Ligature Mark in Death Cases Caused by Hanging and Compression of Neck in Ajmer District R K Boyal, Shiv Kochar

26. Study on Nature of Ligature Material, Knot Type and Pattern of Ligature Mark in Death Cases Caused by Hanging and Ligature Strangulation in Ajmer District

R K Boyal, Shiv Kochar

27. Awareness among Doctors of A Medical College in Southern India of Guidelines and Protocols for Medico-Legal Care for Survivors/Victims of Sexual Violence Priyanka Bhagat, Rajesh Kamath, Bryal D 'Souza, Sagarika Kamath, Rohan Kamath

28. Profile of Deaths Due to Poisoning at A Tertiary Care Centre in North Karnataka Ravindra Kumar C N, Gajanan H Nayak, Sunilkumar S Biradar, Madhu Sudhan S, Mahalaxmi Karlawad, Muthamizh Selvan

29. Profile of Electrocution Fatalities-An Autopsy Study 128 Neha Singh, Richa Choudhury 
30. An Assessment of the Perceptions in the General Population of Sexual Harassment 132 Ananya Ramesh, Sagarika Kamath, Rajesh Kamath, Bryal D’Souza

31. Adverse Drug Reaction in Tertiary Care Hospital of Hilly State 138 Ritu Shitak, Sangeet Dhillon, Malvika Shitak

32. Retrospective Study on Patterns of Homicidal Death in Western Odisha 141 Seema Perei

33. A Study to Assess Knowledge Regarding Medical Ethics among Undergraduates in A Rural Medical College of Mandya District, Karnataka 146 Shreedhara K C, Sidramappa Gouda

34. A Study on Pattern of Injuries in Fatal Cases of Fall From Height in The Rural Areas of Mandya District Shreedhara K C, Sidramappa Gouda

35. Autopsy Profile of Strangulation Deaths in Homicides at A Tertiary Care Teaching Hospital in South India Suraj Sundaragiri, Vijaya Durga Koppada

36. Regression Analysis to Determine Body Weight from Foot Impression Breadth Measurements in Bidayuhs of East Malaysia 158 T. Nataraja Moorthy, Hairunnisa Bt Mohd Anas Khan

37. Body Weight Estimation from Footprint Anthropoetry in Lun Bawang Ethnic of East Malaysia T. Nataraja Moorthy, Hairunnisa Bt Mohd Anas Khan

38. Evaluation of Mandibular Parameters for Gender Assessment by Digital Panoramic Radiography and Its Relevance in Forensic Odontology-A Retrospective Study 170 Tanvi Dosi, Sonal Vahanwala, Dhaman Gupta

39. Handling of Medicolegal Cases by Doctors in Imphal West 176 Abdul Raoof MP, Gitashree Dutta, Th. Meera, Brogen Singh Akoijam, A. Mercy

40. Study of Death Due to Hanging in Southern Marathwada Region of Maharashtra 180 R. R. Khetre, M. E. Bansude, C. R. Dode, R. B. Umbare

41. A Research Study on Deaths Due to Injuries to Abdomen Brought to Ananthapuram Govt. Medical College Mortuary, Andhra Pradesh from January 2010 To December 2016 185 Venati Jayashankar, M. Srinivas Naik

42. Dating of Laceration by Gross and Histo-pathological Examination of skin-A Postmortem Study Vinay J, Mangala Gouri, Akshith Raj S Shetty, S Harish

43. Estimation of Supine Length from Percutaneous Measurement of Hand Length 196 Vishwajeet Singh, Priyal Jain, Anil Kumar Tyagi, Kalyan Kumar Banerjee

44. The Influence of Culture and Society on Mental Health 202 Mahanta Putul, Thakuria Das Kahua, Thakuria Jayanta, Medhi Shobhana 


\title{
About a Case of Anomalous Evolution of the Thanatological Phenomena
}

\author{
Bartolo Caggiano $^{1}$, Matteo Solinas ${ }^{2}$, Francesco Raschellà ${ }^{1}$, Alessandro Feola ${ }^{1}$, Silvestro Mauriello ${ }^{1}$, \\ Saverio Potenza ${ }^{1}$, Luigi T. Marsella ${ }^{1}$ \\ ${ }^{1}$ Department of Biomedicine and Prevention, University of Rome "Tor Vergata", via Montpellier, 1, 00113 \\ Rome, Italy; ${ }^{2}$ Department of Diagnostic, Clinical and Public Health Medicine, Universi-ty of Modena and \\ Reggio Emilia, via del Pozzo, 71, 41124 Modena, Italy
}

\begin{abstract}
The reported case is worthy of reporting because it shows the difficulties encountered in the medico-legal practice in determining of the death time. The Authors highlight the influence of the environmental factors on the thanatological processes and the importance of studying the climatic and microclimate conditions of the environment where the corpse is found. The thanatological phenomena, detected during the crime scene investigation, placed the death time 48-72 hours before the corpse was discovered, while the investigations of the Judicial Police assessed the murder was committed a week before. The anomalous development of the thanatological phenomena was explained as the consequence of the microclimatic conditions, which significantly slowed down the evolution of post-mortal processes, bringing the time of death to a time antecedent to that established. It can be asserted that the earlier the thanatological data are collected in relation to the time of death, the greater is the likelihood of the death time estimate to be correct, as the influence of the environmental factors is reduced.
\end{abstract}

Keywords: postmortem interval, consecutive phenomena, environmental factors, Henssge nomogram, thanatocronology.

\section{INTRODUCTION}

The chronology of the thanatological phenomena has an irregular and never constant pattern due to the variability and multiplicity of influential factors that can be distinguished in "extrinsic factors" to the corpse, such as temperature, humidity, ventilation of places or season, and "intrinsic factors", such as complexion, the cause of death, age or the presence of pathologies. In this report we describe a directly observed case where consecutive thanatological phenomena occurring on a corpse found within a home presented an abnormal chronological trend due to the particular microclimatic conditions that

\section{Corresponding Author:}

Dr. Bartolo Caggiano,

Department of Biomedicine and Prevention, University of Rome "Tor Vergata", via Montpellier, 1, 00113 Rome, Italy

Phone: +3906 72596222

E-mail: bartolocaggiano@gmail.com had been created, underlining the difficulties that can be encountered in the legal practice in establishing the time of death.

Case Report: In February 2013, in late morning, in a Roman coastal location, a corpse of a 65-70 years old male subject was found inside a house. The site inspection started, and before entering inside the house, the outdoor temperature was detected, which was $13.5^{\circ} \mathrm{C}$. The dead body, which was devoid of clothes, was found in a prone position inside the house. Before examining the body, the temperature was measured inside the room where the body laid. It was $15.1{ }^{\circ} \mathrm{C}$. The cadaveric temperature, measured at regular intervals of 30 minutes for two hours by rectal thermometer, was consistently $15.7^{\circ} \mathrm{C}$. The hypostatic spots were of a reddish color, abundantly represented and located in the anterior regions of the body, at the initial phase of absolute fixation, as they were just attenuated by a energetic prolonged massage and no longer migratable to body displacement. The cadaveric rigidity was in process of resolution. Finally, 
there was no apparent transformative phenomenology; in particular, there was no putrefactive green spot. The preliminary inspection of the corpse showed numerous injuries of different nature: lacerated and contused wounds of the head, face ecchymosis, skin lesion at the neck due to strangulation and stab, and puncture and stab wounds to the limbs and trunk posteriorly and laterally. The thanatological phenomena observed during the inspection determined that the time of death was about 48 to 72 hours before the corpse discovery. Henssge's nomogram, knowning the rectal temperature $\left(15.7^{\circ} \mathrm{C}\right)$, environmental temperature $\left(15.1^{\circ} \mathrm{C}\right)$ and body weight $(80 \mathrm{~kg})$, and considering the corrective factors, confirmed the time of death of estimated during the inspection. However, this information was refuted by the investigations of the Judicial Police. In fact, a video surveillance system near the house where the corpse had been found, filmed the murderer and the victim while returning home with the car of the latter the week before. After a few hours, the murderer left the victim's house with the same car without returning. In the week before the discovery of the corpse, nobody came or left the house. This investigative finding, therefore, allowed the age of death to be fixed a week before the corpse was discovered.

\section{DISCUSSION}

The reported case is characterized by an abnormal and singular trend of the thanatological phenomena, which have made the determination of the time of death extremely difficult and complicated. As far as the examination of the time of death is concerned, the following is to be specified. Cadaveric cooling, in standard conditions, occurs in the first 3-4 hours of death with a half-degree decrease in temperature per hour; then in the next 6-10 hours there is a decrease of about one degree per hour and after approximately 14 hours from death, the cadaveric temperature decreases initially three-quarters of degree, then half-degree and finally a quarter degree per hour till it equals the environmental temperature. Temperature leveling occurs on average from 24 to 30 hours. In the aforementioned case, the body temperature $\left(15.7^{\circ} \mathrm{C}\right)$ was in substantial balance with that found inside the room where the body laid $\left(15.1^{\circ} \mathrm{C}\right)$. So the estimate of the time of death, based on the thermal decrease, was to be set beyond thirty hours ago. The hypostatic spots, in standard conditions, generally begin to form after about 30 minutes and become progressively more extended until 10-12 hours after death. Their evolution is characterized by three stages: migratability, relative fixity, and absolute fixity. During the inspection, the corpse had slightly attenuated hypostasis to an energetic long-lasting massage and not modifiable with body displacement, so at an initial absolute fixation stage. The cadaveric stiffness generally begins after about 3-4 hours from death at the level of mimic and masticator muscles. Subsequently, according to Nysten's law, it extends in the skull-caudal direction to all skeletal muscle districts, which will be completely affected after about 7-12 hours. The maximum intensity is reached after about 36-48 hours after death. After that, following the same order of appearance, i.e. in the skull-caudal direction, the stiffness resolution phase begins, which is completed after about $72-80$ hours. The cadaveric stiffness in the present case was, at the time of the inspection, in way of resolution. These consecutive thanatological phenomena were associated with the complete absence of transformative phenomena. Therefore, all the thanatological elements available to us, found during the inspection, supported a death time of about 48-72 hours before the discovery of the corpse. The estimate of the post-mortem interval was confirmed by the nomogram of Henssge ${ }^{1,3}$. This was in strong contrast to the results of the Judicial Police investigations, which placed the criminal event occurrence the week before. The explanation of this phenomenon or of such anomalous tendency in the thanatological phenomena suggests that the microclimatic conditions created in the environment where the corpse was located, significantly slowed down the evolution of post-mortal processes. In this sense, it should be emphasized that the chronology of the hypostatic spots is subject to great variability, especially in relation to the period of fixity initiation, which according to some authors ${ }^{4,5}$ can also occur hundred or more hours after death. Even cadaveric stiffness is influenced by environmental factors, and in particular by the outside temperature. In a study of corpses kept at a constant temperature of $4^{\circ} \mathrm{C}$, the persistence of cadaveric rigidity was observed far beyond the classical limits reported in the literature as it was observed a shift from generalized to partial rigidity between the eleventh and the seventeenth day post mortem ${ }^{6}$. A further study on rigor mortis intensity variations at various environmental temperatures $(6,24$ 
and $37^{\circ} \mathrm{C}$ ) on rats showed that, at low temperatures, there is a gradual and substantial increase in muscle rigidity given by the sum of classic rigor mortis and the so-called "cold rigidity". The action of environmental factors can influence post-mortal transformative processes by favoring an abnormal evolution of the thanatological phenomena. ${ }^{8}$

Under standard conditions, the chromatic phase, the first stage of putrefaction, begins with the appearance of green stain after about 12-18 hours in the summer period and after 1-2 days in winter. This phase, caused by the enzymatic activity of the intestinal tract commensal bacteria, is strongly influenced by the temperature outside of the corpse. In fact, if the ideal temperature for putrefaction is between $21^{\circ} \mathrm{C}$ and $38^{\circ} \mathrm{C}$, because it increases bacterial autolysis, temperatures below $10{ }^{\circ} \mathrm{C}$ block the putrefactory processes ${ }^{9,10}$.

\section{CONCLUSIONS}

The presented case is worthy of reporting because it shows the difficulties encountered in the medico-legal practice in determining of the death time. The examined case emphasizes the influence of environmental factors on the thanatological processes and the importance of studying the climatic and microclimate conditions of the environment where the corpse is found. Nevertheless, it should be noted that environmental surveys are not always feasible and microclimatic conditions are often unmanageable and unverifiable. In the case we report, the thanatological phenomena found during the survey, placed the death time 48-72 hours before the corpse was discovered, but the investigations of the Judicial Police showed how the murder was committed a week before. The explanation of the anomalous development of the thanatological phenomena suggests that in the environment where the corpse was located, microclimatic conditions that significantly slowed down the evolution of post-mortal processes were present, bringing the time of death to a time antecedent to that established. It can therefore be asserted that, in general terms, the earlier the thanatological data are collected in relation to the time of death, the greater is the likelihood of the death time estimate to be correct, as the influence of the environmental factors that can change their evolution is reduced.
Conflict of Interest: The authors have no conflicts of interest to declare.

Ethical Clearance: Informed consent was obtained from legal guardian for uses of the case materials for research purposes and publication findings.

Source of Funding: Self funding.

\section{REFERENCES}

1. Henssge C. Die Präzision von Todeszeitschätzungen durch die mathematische Beschreibung der rektalen Leichenabkühlung. Z Rechtsmed 1929; 83 (1):49-67.

2. Henssge C. Death time estimation in case work. I. the rectal temperature time of death nomogram. Forensic Sci Int 1988; 38 (3-4):209-36.

3. Henssge C. Rectal temperature time of death nomogram: dependence of corrective factors on the body weight under stonger thermic insulation conditions. Forensic Sci Int 1992; 54 (1):51-66.

4. Carella A. Il lavaggio artero-venoso del cadavere applicato allo studio delle macchie ipostatiche. Med Leg Ass 1953; 1:311.

5. Frache G. Tanatologia Forense. Nuove acquisizioni e moderni orientamenti. Minerva Med Leg 1953; 73:5.

6. Varetto L, Curto O. Long persistance of rigor mortis at constant low temperature. Forensic Sci Int 2005; 147 (1): 31-4.

7. Krompecher T. Experimental evaluation of rigor mortis: effect of various temperatures on the evolution of rigor mortis. Forensic Sci Int 1981; 17 (1): 19-26.

8. Marella GL, Perfetti E, Manciocchi S, Arcudi G. A case of "precocious" mummification. J Forensic Leg Med 2013; 20 (2):122-4.

9. Jain B. Guide to Forensic Medicine and Toxicology. $4^{\text {th }}$ ed. New Delhi: B. Jain Publishers Ltd; 2004, 55-59.

10. Vij K. Textbook of Forensic Medicine and Toxicology. $4^{\text {th }}$ ed. New Delhi: Elsevier Ltd; 2008, 112-134. 